\title{
ANALISIS EFEKTIVITAS BIAYA (COST EFFECTIVENESS ANALYSIS) PENGOBATAN INFEKSI SALURAN KEMIH MENGGUNAKAN ANTIBIOTIK SEFTRIAKSON DAN SEFOTAKSIM DI RS PARU ARIO WIRAWAN SALATIGA
}

\author{
Kusumaning Wardhani ${ }^{1}$, Ening Listyanti ${ }^{2}$, Niken Dyahariesti ${ }^{3}$, Richa Yuswantina $^{4}$ \\ Program Studi Farmasi, Universitas Ngudi Waluyo, ${ }^{1,3,4}$ \\ Intalasi Farmasi RSP dr. Ario Wirawan Salatiga ${ }^{2}$ \\ Email : kusumaningwardhani@gmail.com
}

\begin{abstract}
ABSTRAK
Infeksi Saluran Kemih (ISK) adalah keadaan dimana kuman bertumbuh dan berkembangbiak di dalam traktus urinarius dengan jumlah yang bermakna. ISK diobati dengan antibiotik yang menjadi salah satu kategori biaya yang signifikan dalam anggaran farmasi di rumah sakit. Antibiotik golongan Sefalosporin digunakan sebagai drug of choise dan dicari lebih cost-effective. Untuk menentukan terapi yang lebih costeffective antara penggunaan Setriakson dan Sefotaksim pada pasien ISK di rawat inap di RS Paru Ario Wirawan Salatiga. Penelitian ini menggunakan metode penelitian deskriptif dengan pengambilan data secara retrospektif.Dianalisis dengan metode CEA dengan parameter Average Cost Effectiveness Ratio (ACER) dan Incremental Cost Effectiviness Ratio (ICER) dilihat dari outcome lama rawat inap. Sampel pada penelitian ini sebanyak 39 pasien diantaranya 22 pasien menggunakan Seftriakson dan 17 pasien menggunakan Sefotaksim. Hasil penelitian menunjukkan, nilai ACER kelas I Sefotaksim sebesar Rp. 454.353. Nilai ACER kelas II Sefotaksim sebesar Rp. 212.283 dan nilai ICER sebesar -Rp. 134.987/hari. Nilai ACER kelas III Seftriakson sebesar Rp. 268.366. Biaya antibiotik yang paling cost-effective pada kelas I adalah Sefotaksim, paling cost-effective pada kelas II adalah Sefotaksim, paling cost-effective pada kelas III adalah Seftriakson.
\end{abstract}

Kata Kunci : Analisis Efektitas Biaya, Infeksi Saluran Kemih, Seftriakson, Sefotaksim.

\section{ABSTRACT}

Cost Effectiveness Analysis Of Urinary Tract Infections Antibiotics Treatment Used Ceftriaxone And Cefotaxime In Pulmonary Disease Center (Respiratory Disease) Ario Wirawan Salatiga

Urinary Tract Infection (UTI) is a condition in which germs grow and multiply in the urinary tract with significant amounts. Urinary tract infections treated with antibiotics are one of the significant cost catagories in the pharmaceutical budget in hospitals. Antibiotics Sefalosporin by using drug of choiseand sought more cost-effective. to determine a more cost-effective therapy between the use of ceftriaxone and cefotaxime in urinary tract infection (uti) hospitalized patient in Pulmonary Disease Center (Respiratory Disease) Ario Wirawan Salatiga. This study uses a descriptive research method with retrospective data collection. Cost effectiveness analysis is done by calculating direct medical costs and therapeutic effectiveness with the Average Cost Effectiveness Ratio ( ACER)formula and Incremental Cost Effectiveness Ratio (ICER) can be seen from the outcome of length of stay. The Samples in this study were 39 Analisis Efektivitas Biaya...( Kusumaning Wardhani, Niken Dyahariesti,Richa Yuswantina) 
patients including 22 patients using Ceftriaxone and 17 patients using Cefotaxime. The results showed, value ACER class I was Cefotaxime Rp. 454,353. ACER value of Cefotaxime class II was Rp. 212,283 and ICER value of -Rp.134,987/day. ACER value of Ceftriaxone class III was Rp. 268,366. The more cost-effective in the class I is Cefotaxime, more cost-effective in the class II is Cefotaxime, more cost-effective class III is Ceftriaxone.

Keywords: Cost Effectiveness Analysis, Urinary Tract Infection, Ceftriaxone, Cefotaxime.

\section{PENDAHULUAN}

Infeksi saluran kemih (ISK) merupakan salah satu jenis infeksi nosokomial yang angka kejadianya paling tinggi yaitu sekitar 39\%-60\% (Lestari et al, 2011). ISK didefinisikan dengan keadaan dimana kuman tumbuh dan berkembangbiak di dalam traktus urinarius dengan jumlah yang bermakna (Hassan et al, 2007). ISK dapat menyerang semua usia, wanita lebih rentan terkena ISK dari pada pria karena jarak antara kandung kemih dan kulit yang dipenuhi oleh bakteri ialah $5 \mathrm{~cm}$ pada wanita, dibandingkan dengan 20 cm pada pria (Prasetyo et al. 2004).

Berdasarkan survei yang dilakukan di RS Paru Ario Wirawan Salatiga, golongan antibiotik Sefalosporin (Seftriakson dan Sefotaksim) merupakan antibiotik yang banyak digunakan.

Pengobatan ISK sebagian besar menggunakan antibiotik. Untuk menentukan terapi yang paling cost effectiveness dilakukan kajian farmakoekonomi. Cara komperhensif untuk menentukan pengaruh ekonomi dari alternatif terapi obat yaitu dengan analisis farmakoekonomi yang berupa cost effectiveness analysis (CEA) (Andayani,2013).

\section{METODE PENELITIAN}

Jenis dan rancangan penelitian yang digunakan yaitu penelitian deskriptif dengan metode pengambilan data secara retrospektif yang didasarkan pada catatan rekam medik yang membandingkan direct medical cost dari obat Seftriakson dan Sefotaksim pada pasien ISK rawat inapdi RS Paru Ario Wirawan Salatiga. Penelitian ini dilaksanakan di RS Paru Ario Wirawan Salatiga pada bulan Juni 2019. Populasi dalam penlitian ini yaitu seluruh pasien yang didiagnosa mengalami ISK yang menggunakan antibiotik Seftriakson dan Sefotaksim. Sampel dalam penelitian ini sebanyak 39 pasien yang terdiri dari 22 pasien Sefotaksim dan 17 pasien seftriakson yang dimana pasien yang diwawat inapdi RS Paru Ario Wirawan Salatiga periode Januari-Desember 2018 yang memenuhi kriteria sebagai berikut:

a. Kriteria Inklusi

1. Pasien ISK yang menjalani rawat inap usia $\geq 18$ tahun.

2. Pasien yang dirawat inap dengan diagnosis ISK yang mendapatkan terapi antibiotik Seftriakson atau antibiotik Sefotaksim.

3. Pasien ISK dengan status pulang sembuh atau membaik oleh dokter.

4. Pasien yang memiliki data lengkap (nomor RM, umur, jenis kelamin, nama obat, dosis obat, lama menderita, hasil tes lab).

5. Pasien dengan asuransi BPJS.

b. Kriteria Eksklusi

Pasien ISK dengan penyakit infeksi lain.

Data dianalisis dalam bentuk tabel dan secara deskriptif. Setelah data terkumpul dan telah dilakukkan penyuntingan data, dilakukkan 
perhitungan biaya medik langsung pada tiap-tiap pasien. Kemudian dijumlahkan sesuai golongan terapi lalu dibuat rataratanya yang dimana efektivitasnya dilihat dari lama rawat inapnya. Data yang terkumpul dapat digunakan untuk mengitung rata-rata atau Average CostEffectiveness Ratio (ACER).

\section{HASIL DAN PEMBAHASAN}

1. Karakteristik Pasien

Tabel 1. Karakteristik Pasien ISK Di Instalasi Rawat Inap RS Paru Ario Wirawan Salatiga Tahun 2018 Berdasarkan Usia Dan Jenis Kelamin

\begin{tabular}{|l|l|l|}
\hline Kelompok & Jumlah & $\begin{array}{l}\text { Presentase } \\
\%\end{array}$ \\
\hline Usia (tahun) \\
\hline
\end{tabular}

Pada penelitian ini ditemukan bahwa pasien pada kelompok usia $\geq 56$ tahun lebih rentan terkena atau beresiko mengalami ISK, karena pada usia tersebut terjadi penurunan daya imun atau meningkatnya kerentanan terhadap infeksi (Kasmed et al, 2007).Data karakteristrik jenis kelamin pasien ISK memperlihatkan bahwa, pasien berjenis kelamin perempuan lebih banyak yaitu 30 (76,92\%) dibandingkan dengan
$\mathrm{ACER}=\frac{\text { biaya pengobatan }(R p)}{\text { efektivitas pengobatan }(96)}$

dan hasil dari CEA dapat disimpulkan dengan Incremental Cost Effectiveness Ratio (ICER). ICER

biaya $A-b i a y a ~ B$

efektivitas $A$-efektivitas $B(96)$

\begin{tabular}{|c|c|c|}
\hline $18-25$ & 6 & 15,38 \\
\hline $26-35$ & 5 & 12,82 \\
\hline $36-45$ & 4 & 10,26 \\
\hline $46-55$ & 7 & 17,95 \\
\hline$\geq 56$ & 17 & 43,59 \\
\hline Total & 39 & 100 \\
\hline \multicolumn{3}{|c|}{ Jenis kelamin } \\
\hline Laki-laki & 9 & 23,08 \\
\hline Perempuan & 30 & 76,92 \\
\hline Total & 39 & 100 \\
\hline
\end{tabular}

berjenis kelamin laki-laki berjumlah 9 $(23,08 \%)$. Wanita lebih rentan terkena ISK dibandingkan dengan pria (Tjay dan Rahardja, 2007). Wanita mengidap ISK 10 kali lebih rentan dibandingkan pria karena jarak antara kandung kemih dan kulit yang dipenuhi oleh bakteri ialah $5 \mathrm{~cm}$ pada wanita, dibandingkan dengan $20 \mathrm{~cm}$ pada pria (Prasetyo et al, 2004).

\section{Biaya Medik Langsung Pasien}

Tabel 2. Data Biaya Medik Langsung Pasien Infeksi Saluran Kemih Menggunakan Terapi Sefotaksim Di Rawat Inap

\begin{tabular}{|c|c|c|c|c|c|c|c|c|}
\hline \multirow[b]{2}{*}{ No } & \multirow[b]{2}{*}{$\begin{array}{c}\text { Kel } \\
\text { as }\end{array}$} & \multirow[b]{2}{*}{ Pasien } & \multicolumn{4}{|c|}{ Komponen Biaya } & \multirow[b]{2}{*}{$\begin{array}{c}\text { Biaya } \\
\text { Visite } \\
\text { Dokter }\end{array}$} & \multirow[b]{2}{*}{ Total } \\
\hline & & & $\begin{array}{c}\text { Biaya } \\
\text { Pengobatan }\end{array}$ & $\begin{array}{c}\text { Biaya } \\
\text { Laboraturium }\end{array}$ & $\begin{array}{c}\text { Biaya } \\
\text { Ruangan }\end{array}$ & $\begin{array}{c}\text { Biaya Jasa } \\
\text { Perawat }\end{array}$ & & \\
\hline 1 & \multirow{6}{*}{ I } & KSA & 188.298 & 596.100 & 1.100 .000 & 84.000 & 200.000 & 2.168 .398 \\
\hline 2 & & RUA & 128.687 & 596.100 & 1.100 .000 & 74.000 & 150.000 & 2.048 .787 \\
\hline 3 & & $\mathrm{RC}$ & 156.602 & 596.100 & 660.000 & 74.000 & 150.000 & 1.636 .702 \\
\hline 4 & & NSW & 181.982 & 596.100 & 1.100 .000 & 79.000 & 150.000 & 2.107 .082 \\
\hline 5 & & $\mathrm{WN}$ & 206.171 & 596.100 & 880.000 & 89.000 & 100.000 & 1.871 .271 \\
\hline 6 & & IS & 206.785 & 596.100 & 880.000 & 89.000 & 200.000 & 1.971 .885 \\
\hline 7 & \multirow{4}{*}{ II } & OB & 135.047 & 549.100 & 260.000 & 70.000 & 50.000 & 1.064 .147 \\
\hline 8 & & LK & 155.589 & 549.100 & 390.000 & 58.000 & 75.000 & 1.227 .689 \\
\hline 9 & & DF & 125.285 & 549.100 & 520.000 & 62.000 & 75.000 & 1.331 .385 \\
\hline 10 & & JET & 203.732 & 549.100 & 520.000 & 66.000 & 100.000 & 1.438 .832 \\
\hline
\end{tabular}




\begin{tabular}{|c|c|c|c|c|c|c|c|c|}
\hline \multirow[b]{2}{*}{ No } & \multirow[b]{2}{*}{$\begin{array}{c}\text { Kel } \\
\text { as }\end{array}$} & \multirow[b]{2}{*}{ Pasien } & \multicolumn{4}{|c|}{ Komponen Biaya } & \multirow[b]{2}{*}{$\begin{array}{l}\text { Biaya } \\
\text { Visite } \\
\text { Dokter }\end{array}$} & \multirow[b]{2}{*}{ Total } \\
\hline & & & $\begin{array}{c}\text { Biaya } \\
\text { Pengobatan }\end{array}$ & $\begin{array}{c}\text { Biaya } \\
\text { Laboraturium }\end{array}$ & $\begin{array}{c}\text { Biaya } \\
\text { Ruangan }\end{array}$ & $\begin{array}{c}\text { Biaya Jasa } \\
\text { Perawat }\end{array}$ & & \\
\hline 11 & & YM & 261.325 & 549.100 & 910.000 & 74.000 & 150.000 & 1.944 .425 \\
\hline 12 & & $\mathrm{IK}$ & 154.228 & 549.100 & 650.000 & 66.000 & 75.000 & 1.494 .328 \\
\hline 13 & & WD & 190.836 & 549.100 & 650.000 & 70.000 & 75.000 & 1.534 .936 \\
\hline 14 & & $\mathrm{PR}$ & 146.699 & 549.100 & 390.000 & 62.000 & 25.000 & 1.172 .799 \\
\hline 15 & \multirow{3}{*}{ III } & SR & 139.239 & 520.600 & 450.000 & 59.500 & 80.000 & 1.249 .339 \\
\hline 16 & & IR & 135.257 & 520.600 & 300.000 & 63.000 & 80.000 & 1.098 .857 \\
\hline 17 & & $\mathrm{AKD}$ & 109.650 & 520.600 & 375.000 & 59.500 & 60.000 & 1.124 .750 \\
\hline \multicolumn{8}{|c|}{ Total Direct Medical Cost } & 26.485 .612 \\
\hline
\end{tabular}

Dilihat pada tabel 2 perbedaan biaya medik langsung dari masingmasing pasien dikarenakan lamanya pasien dirawat dirumah sakit, karena semakin lama pasien dirawat di rumah sakit maka semakin besar pula biaya yang dikeluarkan pasien. Total direct medical cost atau biaya yang

Tabel 3. Data Biaya Medik Langsung Pasien Infeksi Saluran Kemih Menggunakan Terapi Seftriakson Di Rawat Inap

\begin{tabular}{|c|c|c|c|c|c|c|c|c|}
\hline \multirow[b]{2}{*}{ No } & \multirow[b]{2}{*}{ Kelas } & \multirow[b]{2}{*}{ Pasien } & \multicolumn{4}{|c|}{ Komponen Biaya } & \multirow[b]{2}{*}{$\begin{array}{c}\text { Biaya Visite } \\
\text { Dokter }\end{array}$} & \multirow[b]{2}{*}{ Total } \\
\hline & & & $\begin{array}{c}\text { Biaya } \\
\text { Pengobatan } \\
\end{array}$ & $\begin{array}{c}\text { Biaya } \\
\text { Laboraturium }\end{array}$ & $\begin{array}{c}\text { Biaya } \\
\text { Ruangan } \\
\end{array}$ & $\begin{array}{c}\text { Biaya Jasa } \\
\text { Perawat }\end{array}$ & & \\
\hline 1 & \multirow{8}{*}{ I } & HM & 224.534 & 596.100 & 1.100 .000 & 79.000 & 150.000 & 2.149 .634 \\
\hline 2 & & AHS & 170.713 & 596.100 & 880.000 & 79.000 & 150.000 & 1.875 .813 \\
\hline 3 & & PW & 198.852 & 596.100 & 1.320 .000 & 84.000 & 150.000 & 2.348 .952 \\
\hline 4 & & RA & 131.859 & 596.100 & 880.000 & 79.000 & 150.000 & 1.836 .959 \\
\hline 5 & & FYH & 128.159 & 596.100 & 880.000 & 79.000 & 150.000 & 1.833 .259 \\
\hline 6 & & SR & 425.975 & 596.100 & 2.200 .000 & 104.000 & 400.000 & 3.726 .075 \\
\hline 7 & & SM & 239.049 & 596.100 & 1.100 .000 & 94.000 & 200.000 & 2.229 .149 \\
\hline 8 & & MY & 186.508 & 596.100 & 1.540 .000 & 89.000 & 200.000 & 2.611 .608 \\
\hline 9 & \multirow{6}{*}{ II } & SL & 205.267 & 549.100 & 780.000 & 74.000 & 150.000 & 1.758 .367 \\
\hline 10 & & ERN & 312.083 & 549.100 & 780.000 & 70.000 & 100.000 & 1.811 .183 \\
\hline 11 & & MR & 121.281 & 549.100 & 650.000 & 66.000 & 75.000 & 1.461 .381 \\
\hline 12 & & ST & 105.658 & 549.100 & 650.000 & 58.000 & 75.000 & 1.437 .758 \\
\hline 13 & & SR & 97.807 & 549.100 & 520.000 & 66.000 & 50.000 & 1.282 .907 \\
\hline 14 & & SU & 180.310 & 549.100 & 780.000 & 74.000 & 100.000 & 1.683 .410 \\
\hline 15 & \multirow{6}{*}{ III } & FM & 73.789 & 520.600 & 375.000 & 63.000 & 60.000 & 1.092 .389 \\
\hline 16 & & AP & 157.740 & 520.600 & 225.000 & 70.000 & 60.000 & 1.033 .340 \\
\hline 17 & & $\mathrm{PJ}$ & 173.243 & 520.600 & 375.000 & 63.000 & 60.000 & 1.191 .843 \\
\hline 18 & & $\mathrm{SL}$ & 273.453 & 520.600 & 375.000 & 59.500 & 100.000 & 1.328 .553 \\
\hline 19 & & $\mathrm{SH}$ & 57.297 & 520.600 & 300.000 & 56.000 & 40.000 & 973.897 \\
\hline 20 & & NA & 120.091 & 520.600 & 375.000 & 59.500 & 60.000 & 1.135 .191 \\
\hline
\end{tabular}




\begin{tabular}{|c|c|c|c|c|c|c|c|c|}
\hline \multirow[b]{2}{*}{ No } & \multirow[b]{2}{*}{ Kelas } & \multirow[b]{2}{*}{ Pasien } & \multicolumn{4}{|c|}{ Komponen Biaya } & \multirow[b]{2}{*}{$\begin{array}{c}\text { Biaya Visite } \\
\text { Dokter }\end{array}$} & \multirow[b]{2}{*}{ Total } \\
\hline & & & $\begin{array}{c}\text { Biaya } \\
\text { Pengobatan }\end{array}$ & $\begin{array}{c}\text { Biaya } \\
\text { Laboraturium }\end{array}$ & $\begin{array}{c}\text { Biaya } \\
\text { Ruangan }\end{array}$ & $\begin{array}{c}\text { Biaya Jasa } \\
\text { Perawat }\end{array}$ & & \\
\hline 21 & & SS & 181.120 & 520.600 & 300.000 & 59.500 & 60.000 & 1.121 .220 \\
\hline 22 & & ST & 125.269 & 520.600 & 225.000 & 59.500 & 60.000 & 990.369 \\
\hline & \multicolumn{7}{|c|}{ Total Direct Medical Cost } & 36.913 .257 \\
\hline & \multicolumn{7}{|c|}{ Direct Medical Cost Per Pasien } & 1.677 .875 \\
\hline \multicolumn{5}{|c|}{$\begin{array}{l}\text { Pada tabel } 3 \text { Total } \\
\text { direct medical cost atau biaya yang } \\
\text { dikeluarkan pasien secara langsung } \\
\text { untuk mendapatkan pelayanan } \\
\text { kesehatan dengan mengguanakan }\end{array}$} & \multicolumn{4}{|c|}{$\begin{array}{l}\text { antibiotik Seftriakson untuk ke-22 } \\
\text { pasien yaitu sebesar Rp. } 36.913 .257 \text {, } \\
\text { dengan direct medical cost per pasien } \\
\text { yaitu Rp. } 1.677 .875 \text {. }\end{array}$} \\
\hline
\end{tabular}

3. Efektivitas Terapi (Lama Rawat Inap)

Tabel 3. Outcome Terapi (Lama Rawat Inap)

\begin{tabular}{ccc}
\hline Kelas & Terapi Antibiotik & Rata-rata lama rawat inap (hari) \pm SD \\
\hline \multirow{2}{*}{1} & Sefotaksim & $4,33 \pm 0,82$ \\
\cline { 2 - 3 } & Seftriakson & $5,63 \pm 2,07$ \\
\cline { 2 - 3 } 2 & Sefotaksim & $6,6 \pm 1,55$ \\
\cline { 2 - 3 } 3 & Seftriakson & $5,33 \pm 0,82$ \\
\cline { 2 - 3 } & Sefotaksim & $5 \pm 1$ \\
\cline { 2 - 3 } & Seftriakson & $4,13 \pm 0,99$ \\
\hline
\end{tabular}

Pada tabel 3. Lama rawat inap pada ruang kelas I menggunakan antibiotik Sefotaksim yaitu selama 4,33 hari, lama rawat inap pada antibiotik Seftriakson yaitu selama 5,63 hari.Lama rawat inap pada ruang kelas II menggunakan antibiotik Sefotaksim yaitu selama 6,6

\section{Analisis Kefektifan Biaya}

Tabel 4. Perhitungan ACER Penggunaan Sefotaksi dan Seftriakson pada pasien ISK

\begin{tabular}{ccccc}
\hline $\begin{array}{c}\text { Kelas } \\
\text { perawatan }\end{array}$ & Antibiotik & $\begin{array}{c}\text { Rata-rata direct } \\
\text { Medical Cost } \\
(\mathbf{C})\end{array}$ & $\begin{array}{c}\text { Rata-rata lama hari } \\
\text { rawat inap (Efektivitas) } \\
\text { (E) (Mean) }\end{array}$ & ACER (C/E) \\
\hline \multirow{2}{*}{1} & Sefotaksim & 1.967 .354 & 4,33 & 454.354 \\
\cline { 2 - 5 } & Seftriakson & 2.326 .431 & 5,63 & 413.220 \\
\hline \multirow{2}{*}{2} & Sefotaksim & 1.401 .068 & 6,6 & 212.283 \\
\cline { 2 - 5 } & Seftriakson & 1.572 .501 & 5,33 & 295.028 \\
\hline \multirow{2}{*}{3} & Sefotaksim & 1.157 .649 & 5 & 268.366 \\
\cline { 2 - 5 } & Seftriakson & 1.108 .350 & 4,13 & 212.530 \\
\hline
\end{tabular}

Pada tabel 4 menunjukkan hasil dari perhitungan direct medical cost per pasien yang dibagi rata-rata lama hari rawat inap. ACER pada kelas I Seftriakson yang didapat yaitu Rp. 413.220/hari dan nilai ACER antibiotik Sefotaksim sebesar Rp. 454.353/harisehingga berada pada kolom $\mathrm{G}$ (dominan).ACER pada kelas II Seftriakson yang didapat yaitu Rp. 295.028/hari dan nilai ACER antibiotik hari, lama rawat inap pada antibiotik Seftriakson yaitu selama 5,33 hari.Lama rawat inap pada ruang kelas III menggunakan antibiotik Sefotaksim yaitu selama 5 hari, lama rawat inap pada antibiotik Seftriakson yaitu selama 4,13 hari.
Sefotaksim sebesar Rp. 212.283/hari sehingga berada pada kolom A (ICER).ACER pada kelas III Seftriakson yang didapat yaitu Rp. 268.366/hari dan nilai ACER antibiotik Sefotaksim sebesar Rp. 231.530/hari sehingga berada pada kolom $\mathrm{G}$ (dominan). Biaya penggunaan antibiotik dikatakan efektif apabila mempunyai nilai ACERterendah. Suatu terapi dikatakan cost-effective jika biaya yang 
dikeluarkan serendah mungkin dengan lama perawatan yang cepat. Suatu obat dikatakan cost-effective apabila

Tabel 5. Perhitungan ICER Penggunaan Sefotaksim dan Seftriakson pada pasien ISK pada kelas II mempunyai efektivitas lebih tinggi tetapi harga obat sama atau mempunyai nilai $A C E R$ lebih rendah.

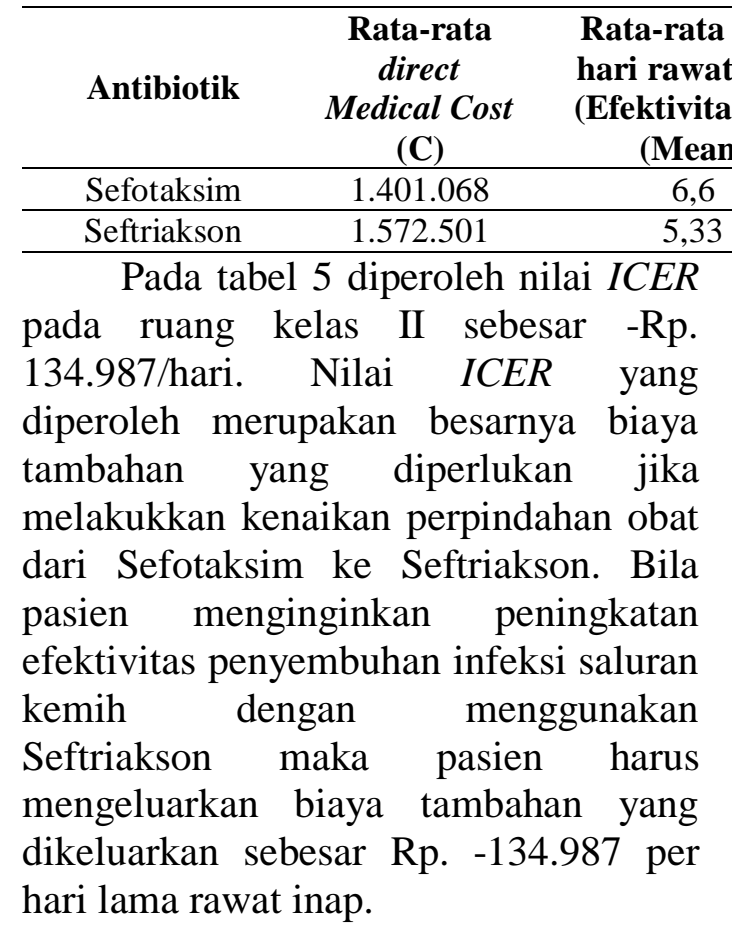

\section{PENUTUP}

\section{Kesimpulan}

a. Pada kelas I antibiotik yang lebih cost-effective adalah Sefotaksim berdasarkan outcomelama terapi dengan nilai ACER Rp. 454.354.

b. Pada kelas II antibiotik yang lebih cost-effective adalah Sefotaksim berdasarkan outcome lama terapi dengan nilai $A C E R$ Rp. 212.283. nilai ICER berdasarkan outcome lama terapi sebesar -Rp. 134.987/hari.

c. Pada kelas III antibiotik yang lebih cost-effective adalah Seftriakson berdasarkan outcomelama terapi dengan nilai ACER Rp. 268.366

\section{Saran}

Dalam analisi efektivitas biaya perlu dilakukan penelitian prospektif

\section{ata lama}

5,33

$\begin{array}{llll}-171.432 & 1,27 & -134.987\end{array}$

dengan melihat keadaan pasien dirawat di RS Paru Ario Wirawan Salatiga.

\section{DAFTAR PUSTAKA}

Lestari W., Ahmady A., Zubir N., et al, (2011). Studi Penggunaan Antibiotik Berdasarkan Sistem ATC/DDD dan Kriteria Gysens di Bangsal Penyakit Dalam RSUP DR.M.Jamil Padang., Tesis., Fakultas Farmasi, Pascasarjana, Universitas Andalas, Padang.

Hassan, R., H. Alatas., A. Latief., P.M. Napitupulu., dan A Pudjiadi. (2007). Ilmu Kesehatan Anak. Infomedika, Jakarta.

Prasetyo, A., B.U. Pendit., dan T. Priliono. (2004). Buku Ajar Patologi Robins. Penerbit Buku Kedokteran EGC, Jakarta.

Andayani, T.M., (2013). Definisi Farmakoekonomi, dalam: Farmakoekonomi Prinsip dan Metodologi. Bursa Ilmu, Yogyakarta, hal. 4.

Kasmed. (2007). Hubungan Antara Kualitas Perawatan Kateter dengan Kejadian Infeksi Nosokomial Saluran Kemih. Universitas Diponegoro, Semarang. 
Tjay, Tan Hoan dan Kirana Rahardja, ( 2007), Obat-Obat Penting Khasiat, Penggunaan dan Efek-
Efek Sampingnya, Edisi Keenam, 262, 269-271, PT. Elex Media Komputindo, Jakarta. 